\title{
ChemComm
}

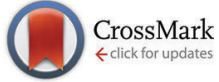

Cite this: Chem. Commun., 2014, 50, 14651

Received 11th September 2014, Accepted 6th October 2014

DOI: $10.1039 / c 4 c c 07173 e$

www.rsc.org/chemcomm

\section{A solvent-free Diels-Alder reaction of graphite into functionalized graphene nanosheets $\dagger$}

\author{
Jeong-Min Seo and Jong-Beom Baek*
}

\begin{abstract}
A solvent-free Diels-Alder reaction was carried out by heating a mixture of graphite and a typical dienophile, maleic anhydride (MA) or maleimide (MI), in a sealed glass ampoule of argon. The functionalization of graphite with dienophiles was confirmed by various characterization techniques, suggesting the efficient functionalization and delamination of graphite into a few layers of graphitic nanosheets.
\end{abstract}

Since the advent of new carbon materials, various attempts to manipulate their properties are constantly conceived. One of the most viable methods is chemical modification, which is the incorporation of functional group(s) by means of covalent or non-covalent bonds. By tuning their intrinsic properties using chemical modification methods, carbon nanomaterials offer a great number of potential applications. ${ }^{1,2}$ However, given the chemical inertness arising from their fully conjugated aromatic network structure, carbon nanomaterials are known to be difficult for functionalization. ${ }^{3}$ Thus, highly reactive chemical species or harsh reaction conditions are required to overcome the large reaction barrier, such as oxidation using a strong $\operatorname{acid}^{4,5}$ or the addition of radicals. ${ }^{6,7}$

To date, several chemical approaches have been developed for modifications of carbon nanomaterials. A promising approach is cycloaddition ${ }^{8}$ owing to the flexibility of the reaction procedure involved and it yields a variety of desirable functional groups. Therefore, numerous studies have been reported on the cycloaddition of fullerenes, ${ }^{9}$ carbon nanotubes, ${ }^{10}$ and the more recently graphene. ${ }^{2}$ Among them, the Diels-Alder reaction, i.e., [4+2] cycloaddition on graphene, was experimentally demonstrated by Haddon's group based on the concept of the dual behaviour of graphene as either a diene or a dienophile. ${ }^{11,12}$ Following their experimental results, $\operatorname{Houk}^{13}$ and Denis ${ }^{14}$

School of Energy and Chemical Engineering/Low-Dimensional Carbon Materials Center, Ulsan National Institute of Science and Technology (UNIST), 100 Banyeon,

Ulsan 689-798, South Korea. E-mail: jbbaek@unist.ac.kr

$\dagger$ Electronic supplementary information (ESI) available: Experimental details, low-magnification HR-TEM image, TGA, Raman characterization, and XPS. See DOI: $10.1039 / \mathrm{c} 4 \mathrm{cc} 07173 \mathrm{e}$ computationally predicted the reaction sites of graphene for Diels-Alder reactions. With regard to the chemistry involved, it is commonly acceptable that organic solvents are necessary to dissolve all of the reactants, allowing them to collide and then react with each other. ${ }^{15}$ However, this principle does not apply for the chemistry of carbon nanomaterials. Most carbon nanomaterials are known to be thermodynamically insoluble in common organic solvents, whereas they form kinetically stable suspensions in amide solvents such as dimethylformamide (DMF) or $N$-methyl-2-pyrrolidone (NMP). In other words, solvents are not always helpful for the functionalization of carbon nanomaterials. Hence, to explore their reactivity in the absence of a solvent is highly challenging. ${ }^{16,17}$

In this communication, we demonstrate a solvent-free Diels-Alder reaction of graphite into functionalized graphene nanosheets using two different dienophiles as an alternative to the solvent-assisted approach. To increase the reaction feasibility conceptually, maleic anhydride (MA) and maleimide (MI) were chosen as the dienophiles for use in this study, whereas graphite was chosen as a diene. In contrast to our previous work in which a mechanochemical approach was used, ${ }^{18}$ thermodynamically preferred reaction products are obtained here, as the reaction is conducted at a relatively high temperature $\left(160-220{ }^{\circ} \mathrm{C}\right)$ in a sealed glass ampoule of argon. We expected that the resultant maleic anhydride-functionalized graphene (MAG) nanosheets and maleimide-functionalized graphene (MIG) nanosheets could be dispersed well in a polar solvent. Furthermore, the functionalization process induces the delamination of the graphite into graphene nanosheets by dispersing the resultant MAG or MIG in a common organic solvent.

The solvent-free Diels-Alder reactions were performed in a closed and sealed system using a glass ampoule of argon (Scheme 1). It should be noted that graphite is a stable material, which, in turn, implies that it has poor reactivity. To facilitate the Diels-Alder reaction, we carried out the reaction at a relatively high temperature $\left(160-220{ }^{\circ} \mathrm{C}\right)$. While conducting the reaction in an open process, MA or MI melted and evaporated, and condensed above the heated zone thus lowering the reactivity 


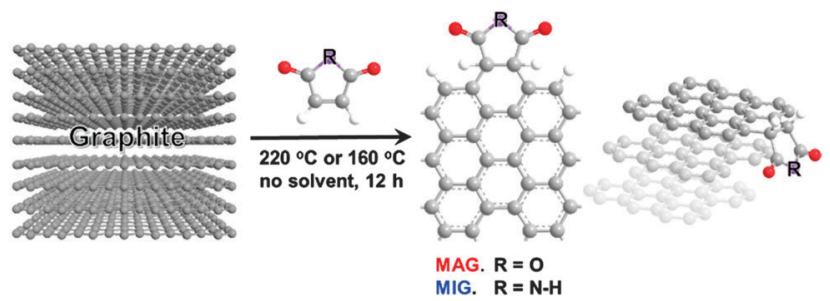

Scheme 1 Schematic representation of the solvent-free Diels-Alder reaction of graphite in the presence of a specific dienophile, maleic anhydride (MA) or maleimide (MI). The red spheres denote the oxygen.

and the reaction yield. Therefore, we utilized a solvent-free procedure using a sealed tube. After the reaction was complete, the products were Soxhlet-extracted with tetrahydrofuran (THF) to remove the unreacted dienophile completely, after which the resultant products were freeze-dried at a reduced pressure and characterized. In both cases, the mass of the product was greater than the mass of the starting graphite (Experimental details, ESI†).

The functionalization of graphene is expected to improve the dispersibility due to the polar functional groups. This prediction is easily confirmed by dispersing the functionalized graphene nanosheets in a polar solvent. For example, MAG and MIG show good dispersibility in NMP, while graphite completely settled down after one month under the same conditions (insets in Fig. 1a-c). Upon exposure to a laser beam, the Tyndall scattering effect was observed for both MAG and MIG. The morphologies of the dispersed solutions were compared by means of scanning electron microscopy (SEM) and transmission electron microscopy (TEM). As shown in Fig. 1 and Fig. S1 in the $\mathrm{ESI}, \dagger$ the grain size is reduced to approximately $1 \mu \mathrm{m}$ compared to pristine graphite. Unlike the graphite (Fig. 1a), the morphologies of MAG and MIG show two-dimensional transparent sheets stacked onto each other (Fig. 1b and c), indicating the efficient functionalization and exfoliation of graphite into a few layers of graphene nanosheets. The exfoliation was further confirmed by

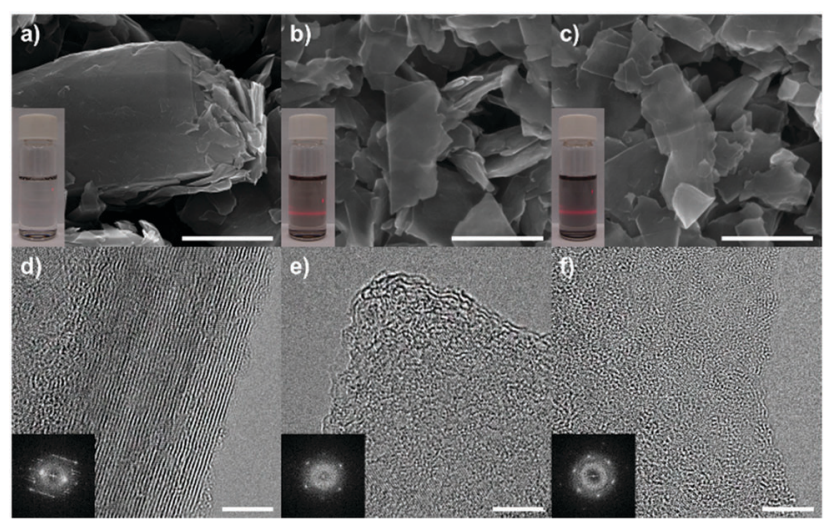

Fig. 1 SEM images: (a) pristine graphite, (b) MAG, and (c) MIG. Scale bars are $1 \mu \mathrm{m}$. Insets in each case are photographs of the sample dispersion in NMP after standing for 1 month under normal laboratory conditions. The concentration is $0.5 \mathrm{mg} \mathrm{ml}^{-1}$. HR-TEM images: (d) pristine graphite, (e) MAG, and (f) MIG. Scale bars are $5 \mathrm{~nm}$. Insets are SAED patterns of each respective sample.
TEM analysis (Fig. 1 and Fig. S1, ESI $\dagger$ ). Compared to pristine graphite (Fig. 1d), MAG (Fig. 1e) and MIG (Fig. 1f) clearly show a few layers of sheets. These results indicate that functionalization induces further delamination of MAG and MIG in a solution to form fewer graphitic layers.

It has been reported that graphene can function as either a diene or a dienophile in a Diels-Alder reaction. ${ }^{11}$ Because we use two dienophiles (MA and MI) as the $2 \pi$ component here, graphite should function as a $4 \pi$ component. Therefore, the reaction is expected to occur at the basal plane and the peripheral positions, especially at the armchair edges. According to the computational prediction reported by Houk's group, ${ }^{13}$ the basal plane of graphene cannot be functionalized, and functionalization occurs only at the armchair edges. The limited number of functionalization sites, therefore, could influence the degree of functionalization. Thus, we performed thermogravimetric analysis (TGA) to identify the degree of functionalization by thermally stripping off the MA and MI moieties from MAG and MIG, respectively. Compared to pristine graphite, the TGA thermograms of MAG and MIG (Fig. S2, ESI $\dagger$ ) obtained in an air atmosphere showed a gradual weight loss starting at approximately $200{ }^{\circ} \mathrm{C}$, with the weight losses of MAG and MIG being approximately 2 and $1 \mathrm{wt} \%$, respectively, at around $500{ }^{\circ} \mathrm{C}$ in air.

To investigate the structural information of MAG and MIG further, the Raman spectra (Fig. S3, ESI $\dagger$ ) were obtained from powdered samples. While pristine graphite has the D- to G-band intensity level $\left(I_{\mathrm{D}} / I_{\mathrm{G}}\right)$ ratio of 0.20 , MAG and MIG have stronger intensity ratios of 0.54 and 0.52 , respectively, which is indicative of a structural defect induced by covalent functionalization. The types of functional groups of the resultant MAG and MIG can be confirmed by Fourier transform infrared (FT-IR) spectroscopy and X-ray photoelectron spectroscopy (XPS). Pristine graphite shows a strong $\mathrm{C}=\mathrm{C}$ stretching band at $1580 \mathrm{~cm}^{-1}$ and shows other minor bands as well due to the physically adsorbed oxygen $\left(1220 \mathrm{~cm}^{-1}\right)$ and moisture (1630, $\left.3430 \mathrm{~cm}^{-1}\right) .{ }^{19}$ On the other hand, MAG and MIG display a decisive difference from the graphite. The first is the presence of strong bands at approximately 2800 and $2900 \mathrm{~cm}^{-1}$, corresponding to $\mathrm{sp}^{3} \mathrm{C}-\mathrm{H}$ stretching attributed to the Diels-Alder reaction. ${ }^{11}$ The second difference results from the carbonyl $(\mathrm{C}=\mathrm{O})$ functionality of MAG and MIG. MAG exhibits a strong $\mathrm{C}=\mathrm{O}$ band at around $1730 \mathrm{~cm}^{-1}$, corresponding to the carboxylic acid moieties, and a weak band at 1780 and $1880 \mathrm{~cm}^{-1}$, which is attributed to the anhydride moieties (Fig. 2a, right) (mostly the anhydrides show two stretching bands for $\mathrm{C}=\mathrm{O}$ groups; the results are from the asymmetrical $\left(1860 \mathrm{~cm}^{-1}\right)$ and symmetrical $\left(1780 \mathrm{~cm}^{-1}\right) \mathrm{C}=\mathrm{O}$ stretching modes. $\left.{ }^{20}\right)$. These results suggest that anhydride groups on MAG are mostly hydrolyzed into carboxylic acid. MIG also has strong $\mathrm{C}=\mathrm{O}$ stretching or overlapped $\mathrm{N}-\mathrm{H}$ bending from the imide ring moieties at $1711 \mathrm{~cm}^{-1}$, with a weak $\mathrm{C}-\mathrm{N}$ band at $1400 \mathrm{~cm}^{-1}$, which is identical to that in maleimide. As a result, the functionality of MIG retains its maleimide moieties compared to the MAG functionalities, which were mostly hydrolyzed into carboxylic acid.

For more detailed information into the characteristics of the bonds, both MAG and MIG were further examined by XPS. 

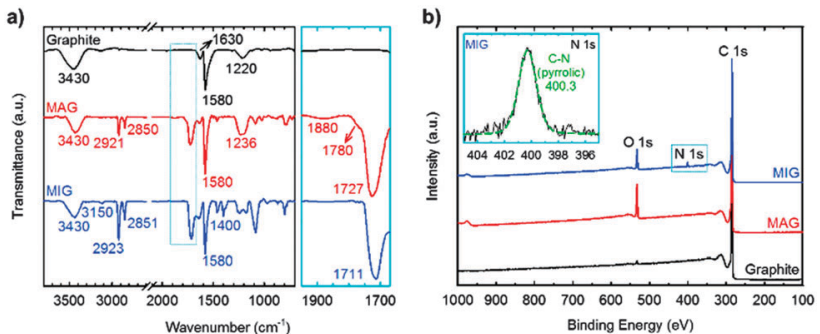

Fig. 2 (a) Full FT-IR spectra (KBr pellets) (left) and magnified spectra (right); (b) XPS survey spectra. Inset: high-resolution XPS N 1s spectrum of MIG.

Pristine graphite exhibits a very minor $\mathrm{O} 1 \mathrm{~s}$ peak at $532 \mathrm{eV}$ relative to the $\mathrm{C} 1 \mathrm{~s}$ peak at $284 \mathrm{eV}$ due to the physically adsorbed oxygen. ${ }^{19}$ MAG and MIG display much stronger $\mathrm{O}$ 1 s peaks owing to the MA and MI functional groups (Fig. $2 \mathrm{~b}$ and Table S1, ESI $\dagger$ ). The deconvoluted high-resolution XPS spectra in the C 1s region of MIG (Fig. S4, ESI $\dagger$ ) show one distinctive peak at $285.6 \mathrm{eV}$, which is attributed to $\mathrm{C}-\mathrm{N}$ bonding of MI moieties. In the case of the $\mathrm{O} 1 \mathrm{~s}$ region, MAG (Fig. S5, ESI $\dagger$ ) shows one broad peak at around $532 \mathrm{eV}$, which is assignable to $\mathrm{C}-\mathrm{O}$ and $\mathrm{C}=\mathrm{O}$ bonding of the MA moieties. MIG also shows two oxygen peaks. Based on the general structure of MI, a single oxygen signal is expected for the carbonyl groups in the imide ring. Beside the main carbonyl peak located at $531.8 \mathrm{eV}$, an additional oxygen peak at $533.3 \mathrm{eV}$ in the range of the $\mathrm{C}-\mathrm{O}$ bond (Fig. S5, ESI $\dagger$ ) was noted. Similar phenomena have been reported in imide-functionalized carbon materials. ${ }^{21}$ While peak asymmetry was observed in the $\mathrm{O} 1 \mathrm{~s}$ envelope, a single $\mathrm{N} 1 \mathrm{~s}$ signal was observed only at $400.3 \mathrm{eV}$, which corresponds to the pyrrolic-N of the imide ring (Fig. 2b, inset). Thus, we can conclude that, once again, the MI rings on MIG remain intact during work-up procedures.

We have, for the first time, demonstrated a solvent-free DielsAlder reaction of graphite using two different dienophiles, maleic anhydride and maleimide. The covalent functionalization of graphite could be a driving force for its delamination into graphene nanosheets through dispersion in a polar solvent such as DMF or NMP. Hence, the solvent-free covalent functionalization of graphite via the Diels-Alder reaction is not only a simple but an efficient approach for the scalable preparation of graphene nanosheets.

\section{Notes and references}

1 Y.-P. Sun, K. F. Fu, Y. Lin and W. J. Huang, Acc. Chem. Res., 2002, 35, 1096.

2 V. Georgakilas, M. Otyepka, A. B. Bourlinos, V. Chandra, N. Kim, K. C. Kemp, P. Hobza, R. Zboril and K. S. Kim, Chem. Rev., 2012, 112, 6156.

3 E. Vázquez, F. Giacalone and M. Prato, Chem. Soc. Rev., 2014, 43, 58. 4 V. Datsyuk, M. Kalyva, K. Papagelis, J. Parthenios, D. Tasis, A. Siokou, I. Kallitsis and C. Galiotis, Carbon, 2008, 46, 833.

5 W. S. Hummers and R. E. Offeman, J. Am. Chem. Soc., 1958, 80, 1339.

6 M. S. Strano, C. A. Dyke, M. L. Usrey, P. W. Barone, M. J. Allen, H. W. Shan, C. Kittrell, R. H. Hauge, J. M. Tour and R. E. Smalley, Science, 2003, 301, 1519.

7 E. Bekyarova, M. E. Itkis, P. Ramesh, C. Berger, M. Sprinkle, W. A. de Heer and R. C. Haddon, J. Am. Chem. Soc., 2009, 131, 1336.

8 K. C. Nicolaou, S. A. Snyder, T. Montagnon and G. Vassilikogiannakis, Angew. Chem., Int. Ed., 2002, 41, 1668.

9 A. Hirsch and M. Brettreich, Fullerenes: Chemistry and Reactions, Wiley-VCH Verlag GmbH \& Co. KGaA, Weinheim, FRG, 2005, ch. 4, pp. 101-183.

10 D. Tasis, N. Tagmatarchis, A. Bianco and M. Prato, Chem. Rev., 2006, 106, 1105.

11 S. Sarkar, E. Bekyarova, S. Niyogi and R. C. Haddon, J. Am. Chem. Soc., 2011, 133, 3324.

12 S. Sarkar, E. Bekyarova and R. C. Haddon, Acc. Chem. Res., 2012, $45,673$.

13 Y. Cao, S. Osuna, Y. Liang, R. C. Haddon and K. N. Houk, J. Am. Chem. Soc., 2013, 135, 17643.

14 P. A. Denis, Chem. - Eur. J., 2013, 19, 15719.

15 P. Pollet, E. A. Davey, E. E. Ureña-Benavides, C. A. Eckert and C. L. Liotta, Green Chem., 2014, 16, 1034.

16 C. A. Dyke and J. M. Tour, J. Am. Chem. Soc., 2003, 125, 1156.

17 E. V. Basiuk, M. Monroy-Peláez, I. Puente-Lee and V. A. Basiuk, Nano Lett., 2004, 4, 863.

18 J.-M. Seo, I.-Y. Jeon and J.-B. Baek, Chem. Sci., 2013, 4, 4273.

19 C. Hontoria-Lucas, A. J. López-Peinado, J. D. D. López-González, M. L. Rojas-Cervantes and R. M. Martín-Aranda, Carbon, 1995, 33, 1585.

20 S. R. Gaboury and M. W. Urban, Langmuir, 1993, 9, 3225.

21 K. C. Yung, D. W. Zeng and T. M. Yue, Appl. Surf. Sci., 2001, 173, 193. 